\title{
Applanation ocular tension in myopia and emmetropia
}

\author{
M. I. ABDALLA AND M. HAMDI \\ From the Department of Ophthalmology, Ain Shams University Hospitals, Cairo, Egypt
}

Many factors determine the individual intraocular pressure in a given eye and the mean level in a given population. When it is estimated by indentation tonometry, such variables as the corneal curvature and rigidity, the scleral rigidity, and the initial ocular volume, have all been found to influence the readings (Friedenwald, I937; Phillips and Quick, I 960), but these are much less important when applanation tonometry is used because of the small volumetric displacement (Goldmann, I957; Schmidt, I959).

Friedman ( 1966) showed that differences in the initial volume of the eye affect the stressstrain relationship in the ocular coats, and this may cause variations in tonometric readings, even when the applanation method is used.

Direct determination of the volume of the living eye is difficult but, as there is known to be a correlation between the refraction of the eye and its axial length (and therefore it volume) (Sorsby, Benjamin, Davey, Sheridan, and Tanner, 1957), errors of refractiog may influence applanation readings.

The aim of this paper is to report the results of a comparison of applanation tonometric readings in 760 emmetropic and myopic eyes examined at Ain Shams University Hospitals during the year 1967 .

\section{Material and methods}

Subjects were selected from patients attending the ophthalmic out-patients clinic for refraction and from normal persons accompanying their sick relatives. They were all above the age of io years, and their eyes were healthy with no corneo-scleral damage past or present that might have interfered with the measurement of the intraocular pressure.

After the visual acuity had been assessed, the ocular tension was measured with the Goldmann applanation tonometer mounted on the Haag-Streit 900 slit lamp. Homatropine 2 per cent. was then instilled into each eye and one hour later a refraction was done and the results recorded. All eyes with an applanation reading above $20 \mathrm{~mm}$. $\mathrm{Hg}$ or below $10 \mathrm{~mm}$. $\mathrm{Hg}$ were excluded from the study.

All those examined were divided into five age groups and these were subdivided according to the state of refraction (Table I, opposite):

(I) Emmetropia: less than $\pm 2 \mathrm{D}$ sph.

(2) Myopia I: moderate myopia ranging from $-2 \mathrm{D}$ to $-6 \mathrm{D}$ sph., with astigmatism less than 2 D cyl.

(3) Myopia 2: more than $-6 \mathrm{D}$ sph., with astigmatism less than $2 \mathrm{D}$ cyl. 
Table I Distribution of 760 subjects by age group and refractive error

\begin{tabular}{|c|c|c|c|c|}
\hline \multirow{2}{*}{$\begin{array}{l}\text { Age group } \\
\text { (yrs) }\end{array}$} & \multirow{2}{*}{ Emmetropia } & \multicolumn{2}{|c|}{ Myopia } & \multirow{2}{*}{$\begin{array}{l}\text { Total } \\
\text { subjects }\end{array}$} \\
\hline & & I & 2 & \\
\hline I I -20 & 75 & 39 & 18 & 132 \\
\hline $2 \mathrm{I}-30$ & $9^{\circ}$ & 19 & 25 & 134 \\
\hline $3^{1-40}$ & 148 & 19 & 28 & 195 \\
\hline $4^{1-50}$ & I 44 & I I & 34 & 189 \\
\hline Above $5^{\circ}$ & 78 & I 7 & 15 & IIO \\
\hline Total subjects & 535 & 105 & 120 & 760 \\
\hline
\end{tabular}

\section{Results}

The data were analysed statistically to determine whether there was any significant correlation between the refractive state and the mean applanation readings in each group. The mean tensions in myopic and emmetropic eyes were compared and Student's " $t$ " test was applied to determine whether the differences were significant (Table II).

In all age groups the mean values for applanation tensions in myopes were higher than in emmetropes, but the differences were not always significant in all age groups. These findings are clearly apparent in Table II.

Table II Mean ocular tension $(\mathrm{mm} . \mathrm{Hg})$, by age group and refraction

\begin{tabular}{|c|c|c|c|c|c|c|c|c|}
\hline \multirow{3}{*}{$\begin{array}{l}\text { Age } \\
\text { group } \\
\text { (yrs) }\end{array}$} & \multirow{3}{*}{ Refraction } & \multirow{3}{*}{$\begin{array}{l}\text { No. of } \\
\text { subjects }\end{array}$} & \multirow{2}{*}{\multicolumn{3}{|c|}{ Ocular tension $(\mathrm{mm} . \mathrm{Hg})$}} & \multicolumn{3}{|c|}{ Comparison of myopic with emmetropic eyes } \\
\hline & & & & & & " $t$ "value & & \\
\hline & & & 8) & (1) & (2) & Calculated & Tabulated & stgry cсапе \\
\hline I $1-20$ & $\begin{array}{l}\text { Emmetropia } \\
\text { Myopia I } \\
\text { Myopia } 2\end{array}$ & $\begin{array}{l}75 \\
39 \\
18\end{array}$ & $\begin{array}{l}14 \cdot 05 \\
15 \cdot 73 \\
14.61\end{array}$ & $\begin{array}{l} \pm 2 \cdot 24 \\
\pm 1.92 \\
\pm 2.58\end{array}$ & $\begin{array}{l} \pm 0.26 \\
\pm 0.31 \\
\pm 0.6 I\end{array}$ & $\begin{array}{l}3 \cdot 93 \\
0 \cdot 92\end{array}$ & $\begin{array}{l}3 \cdot 37 \\
\mathbf{1} \cdot 98\end{array}$ & $\begin{array}{l}\mathrm{P}<0.00 \mathrm{I}^{*} \\
\mathrm{P}>0.05\end{array}$ \\
\hline $2 \mathrm{I}-30$ & $\begin{array}{r}\text { Emmetropia } \\
\text { Myopia I } \\
2 \\
\end{array}$ & $\begin{array}{l}90 \\
19 \\
25\end{array}$ & $\begin{array}{l}13 \cdot 72 \\
14.53 \\
14 \cdot 48 \\
\end{array}$ & $\begin{array}{l} \pm 2 \cdot 40 \\
\pm 1 \cdot 44 \\
\pm 2 \cdot 62 \\
\end{array}$ & $\begin{array}{l} \pm 0.25 \\
\pm 0.33 \\
\pm 0.52 \\
\end{array}$ & $\begin{array}{l}I \cdot 45 \\
I \cdot 40 \\
\end{array}$ & $\begin{array}{l}\mathbf{I} \cdot 98 \\
\mathbf{I} \cdot 98\end{array}$ & $\begin{array}{l}P>0.05 \\
P>0.05\end{array}$ \\
\hline $3 \mathrm{I}-40$ & $\begin{array}{l}\text { Emmetropia } \\
\text { Myopia I } \\
2\end{array}$ & $\begin{array}{r}\text { 1 } 48 \\
19 \\
28\end{array}$ & $\begin{array}{r}14 \cdot 19 \\
14 \cdot 70 \\
16 \cdot 58 \\
\end{array}$ & $\begin{array}{r} \pm 2 \cdot 01 \\
\pm 2 \cdot 14 \\
\pm 2 \cdot 32 \\
\end{array}$ & $\begin{array}{l} \pm 0 . \text { I I } \\
\pm 0.49 \\
\pm 0.44\end{array}$ & $\begin{array}{l}1 \cdot 03 \\
5 \cdot 60 \\
\end{array}$ & $\begin{array}{l}\text { I } \cdot 96 \\
3 \cdot 29\end{array}$ & $\begin{array}{l}\mathrm{P}>0.05 \\
\mathrm{P}<0.00 I^{*}\end{array}$ \\
\hline $4^{I-50}$ & $\begin{array}{l}\text { Emmetropia } \\
\text { Myopia I } \\
2\end{array}$ & $\begin{array}{r}\text { I } 44 \\
\text { I I } \\
34 \\
\end{array}$ & $\begin{array}{l}14 \cdot 39 \\
16 \cdot 05 \\
15 \cdot 33 \\
\end{array}$ & $\begin{array}{l} \pm 2 \cdot 22 \\
\pm 2 \cdot 83 \\
\pm 2 \cdot 69\end{array}$ & $\begin{array}{l} \pm 0.19 \\
\pm 0.85 \\
\pm 0.46\end{array}$ & $\begin{array}{l}2 \cdot 32 \\
2 \cdot 12\end{array}$ & $\begin{array}{l}\text { I } \cdot 96 \\
\text { I } 96\end{array}$ & $\begin{array}{l}\mathrm{P}<0.05^{*} \\
\mathrm{P}<0.05^{*}\end{array}$ \\
\hline Over $5^{\circ}$ & $\begin{array}{l}\text { Emmetropia } \\
\text { Myopia I } \\
2\end{array}$ & $\begin{array}{l}78 \\
17 \\
15\end{array}$ & $\begin{array}{l}14 \cdot 87 \\
16 \cdot 03 \\
16 \cdot 00\end{array}$ & $\begin{array}{l} \pm \mathbf{I} \cdot 88 \\
\pm 2 \cdot 50 \\
\pm \mathbf{I} \cdot 34\end{array}$ & $\begin{array}{l} \pm 0.21 \\
\pm 0.60 \\
\pm 0.35\end{array}$ & $\begin{array}{l}2 \cdot 14 \\
2 \cdot 20\end{array}$ & $\begin{array}{l}\text { I } \cdot 98 \\
\text { I } \cdot 98\end{array}$ & $\begin{array}{l}\mathrm{P}<0.05^{*} \\
\mathrm{P}<0.05 *\end{array}$ \\
\hline
\end{tabular}

* Difference between ocular tension in emmetropic and myopic eyes significant

\section{Discussion}

The factors most likely to be responsible for differences in applanation readings are the thickness of the cornea, the volume of the eye, and the accommodation. Goldmann 
(1957) reported that pliability of the cornea affected the force needed to flatten a given area, and that the extra force required was equal to that exerted by surface tension if the diameter of the applanation was $3.06 \mathrm{~mm}$. Murata and Kato (1963) measured the thickness of different areas of the cornea, in emmetropia and ametropia, using a corneal pachometer, and found that the mean thickness in the centre of the cornea was $0.53^{2}$, 0.487 , and $0.536 \mathrm{~mm}$. in emmetropic eyes, myopic eyes above $-5 \mathrm{D}$ sph., and hypermetropic eyes above +2 D sph., respectively. There was thus no significant difference between emmetropic and hypermetropic eyes, but a significant difference between emmetropic and myopic eyes. Shukla (1968) confirmed that the cornea is thinner in myopia than in emmetropia, and this probably applies to the sclera as well. Friedman ( 1966) showed that an eye of large volume with thin coats will experience greater stress on its coats than a normal eye at the same intraocular pressure. This greater stress means that more force is required in using the applanation tonometer, thus giving higher tension readings.

Friedenwald (1937) showed that variations in the radius of curvature of the cornea affected indentation tonometric readings, but Schmidt (1959) showed that such variations had very little effect on the results of applanation tonometry; the volumetric displacement in applanation tonometry of a cornea with a radius of curvature of $4.5 \mathrm{~mm}$. was $0.995 \mathrm{cu}$. $\mathrm{mm}$., while that of $15.5 \mathrm{~mm}$. was $0.28 \mathrm{I} \mathrm{cu}$. $\mathrm{mm}$. This very small difference in volume displacement between these extreme radii of curvature of the cornea could not be compared with the large volumetric displacement that occurs in indentation tonometry. Variations in the radius of curvature of cornea cannot therefore explain our results.

Friedenwald (1937), in calculating his formula for ocular rigidity, assumed that then volume of the eye is roughly constant. Phillips and Quick (1960) proved that the amoun of indentation, apart from the other factors, is also dependent on the initial volume of the eye, and that eyes with different volumes but with equal internal pressure, would give different indentation tonometric readings. Friedman (1966) agreed with Phillips and Quick, but added that volume relationships in both applanation and indentation tonometric readings should be considered in calculating measurements of the intraocular pressure. He proved that eyes of different volumes have a different stress-strain relationship in all their coats, in spite of having the same intraocular pressure, so that this stress-strain relationship will affect tonometric readings whatever method is applied. Friedman concluded that in myopia there is no regular variation in ocular rigidity, but rather an average for each degree of refraction modified by age.

Sato, quoted by Becker and Gay (1959) in a monograph on myopia, demonstrated that the axial length of myopic eyes does not increase gradually and proportionately with the refractive error, but that there is a sharp increase between -2 and $-5 \mathrm{D}$ sph., after which the increase in the axial length is small but gradual. Toselli (196r), studying the course and evolution of myopia in the first three decades of life, found that myopia showed a progressive phase with quiescent intervals in 96.5 per cent. of myopes aged 2 to 20 years, only 3.5 per cent. remaining stationary, whereas in those aged 20 to 30 years the myopia remained stationary in 12 per cent. The work of Sato and of Toselli (196I) may explain the differences obtained in cases of moderate myopia in the second decade of life in our series; the marked growth of the eye changes its volume and perhaps the stress-strain characteristics of the cornea, so affecting the applanation tonometric readings.

Levene (196i), Draeger (r96i), Fukuda (I96r), Diaz-Dominguez (I96i), and Armaly (1965) found that the intraocular pressure increased with age. The same result was found in our series, the increment being more pronounced and statistically significant in older 
myopes. The other likely explanation of the significant results obtained in our series in myopes above 40 years of age may be the different thickness of the ocular coats in myopia, which is also modified by changes in the volume and age.

Finally, the factor of accommodation should be considered in discussing the difference in applanation tonometric readings between myopes and emmetropes. Armaly and Burian ( 1958) and Armaly and Rubin ( I 96 I) found that eyes with powerful ciliary muscles have a lower intraocular pressure than those with weaker ciliary muscles when accommodation takes place during tonometry. It is possible that the difference in mean tension between the emmetropes and myopes in our series is partly due to this cause.

\section{Conclusion}

The results of a study of 760 subjects demonstrate a significant relationship between applanation pressure and errors of refraction, and indicate that the patient's age should also be taken into account.

The significant differences between emmetropes and myopes are due to biological variations related to the structure and thickness of the cornea, accommodation, and the volume of the eye.

\section{References}

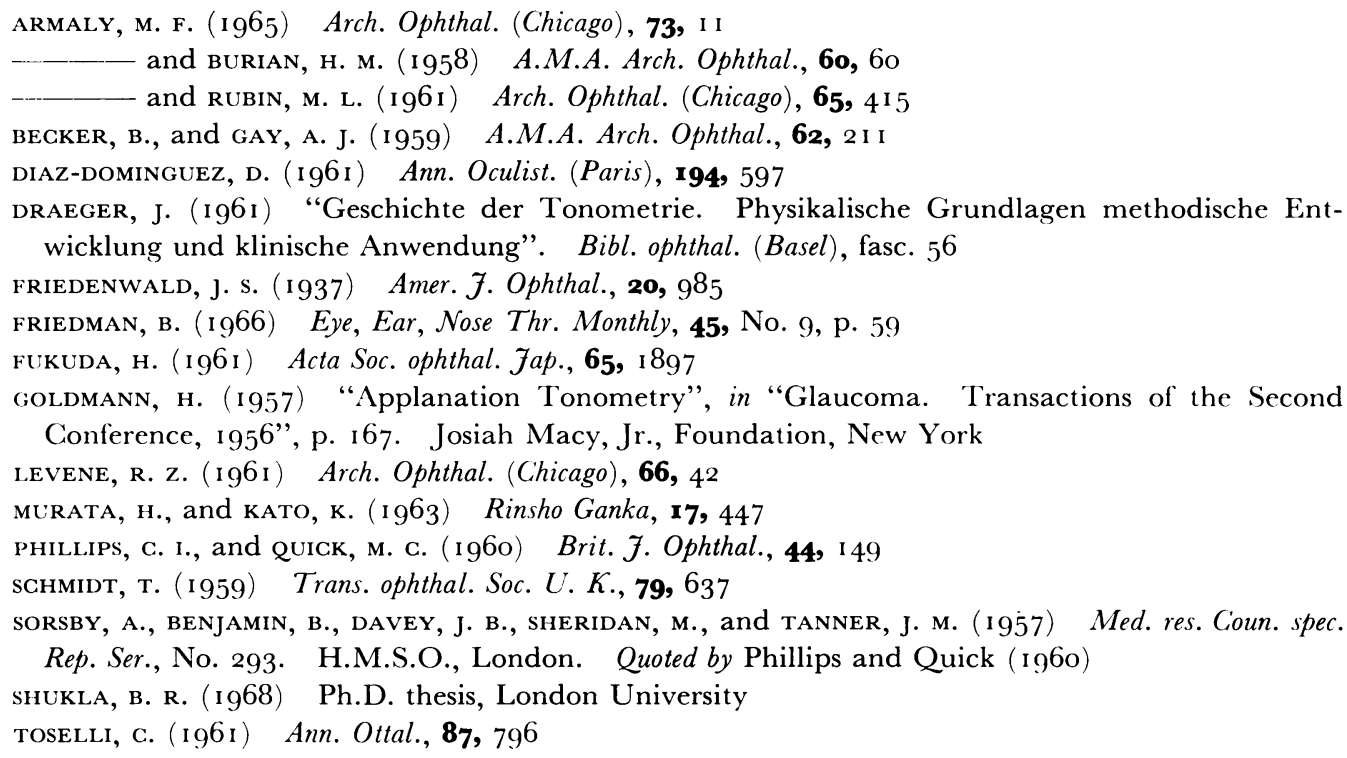

